\title{
Genetic Testing of Inbred Lines and Single Cross Hybrids against Fusarium Stalk Rot Caused by Fusarium moniliforme in Maize (Zea mays L.)
}

\author{
R. Archana ${ }^{1}$, H. C. Lohithaswa ${ }^{1}$, R. Pavan ${ }^{1}$, B. N. Swathi ${ }^{1}$ and N. Mallikarjuna ${ }^{2}$ \\ ${ }^{1}$ Department of Genetics and Plant Breeding, College of Agriculture, \\ ${ }^{2}$ AICRP (Maize), Zonal Agricultural Research Station, V. C. Farm, Mandya, UAS-Bangalore - \\ 571405, Karnataka, India \\ *Corresponding author
}

\section{A B S T R A C T}

\section{Keywords}

Fusarium stalk rot, inbred lines, Single cross hybrids, Resistance

Article Info

Received:

14 October 2021

Accepted:

02 November 2021

Available Online:

10 November 2021
Globally, Maize (Zea mays L.) is a third major cereal food crop. It is a multipurpose crop with $26 \%$ of its production is used as food by human beings. Maize is known as "queen of cereals", because of its high genetic yield potential, efficient utilization of radiant energy and wider adaptability. About 65 different phytopathogens affect the maize production in different stages of life cycle. Among which Fusarium moniliforme is one such soil borne pathogen causes Fusarium stalk rot (FSR) disease that ultimately reduces maize yield potential over the world. In any breeding program, screening and genetic testing of available germplasm resources against pathogens is necessary to prevent yield losses. Hence, the present research screened around 114 maize inbred lines and 45 single cross hybrids (SCHs) against FSR under artificial epiphytotic conditions. Among 114 inbreds, only four inbreds viz., CM 202, 10878, MAI-759 and MAI-766 (mean disease score of 3-4) showed moderately resistant reaction and out of $45 \mathrm{SCHs}$, only one hybrid combination i.e., MAI329 $\times$ CM202 (mean disease score was 2.60) exhibited resistance reaction against Fusarium stalk rot. Nevertheless, these resistance sources could be utilized in maize breeding programs for obtaining high yielding cultivars with resistance towards FSR disease.

\section{Introduction}

Maize (Zea mays L.) is a promising staple cereal crop next to wheat and rice in terms of production globally. It serves as a basic meal, livestock feed, and a raw resource for industry (Troyer, 2006). Approximately $26 \%$ of the country's maize production is eaten as food. Its high-yielding rank among the world's major crops is largely attributable to its excellent utilization of photosynthetic solar energy and carbon dioxide fixation (C4 pathway) from the environment (Anita, 2016)). Because of its tremendous production potential, versatility and flexibility, maize is renowned as the "Queen of Cereals" (Tabassum et al., 2020). Maize production also has the lowest economics when compared to other crops. The major maize-cultivating countries include the United States, China, 
Brazil, India, Mexico, and Argentina. In India, the foremost maize growing states include Karnataka, Andhra Pradesh, Bihar, Madhya Pradesh, Maharashtra, Punjab, Rajasthan, and West. However, maize monoculture and genetic homogeneity (using of similar genetic background in maize breeding programs) allow diseases to proliferate easily (Power, 1987; Liu et al., 2003). Over the world, nine percent of the yield losses were estimated to be caused by diseases alone (Oerke, 2005). Maize is infected by over 65 pathogens, including fungus and bacteria that cause foliar diseases, ear rot, and stalk rots (Rahul and Singh, 2002). Fungi are the most important phytopathogens in maize cultivation, with Fusarium spp. being one of the most serious threats because they can infect roots, stalks, kernels, and ears (Holbert et al., 1924; Munkvold, 2003). Fusarium stalk rot (FSR), caused by Fusarium moniliforme, is one of the most severe soil-borne maize diseases, affecting maize production on every continent. Rajasthan, Uttar Pradesh, Bihar, Karnataka, and Andhra Pradesh are some of the states where the disease is prevalent. Early in the season, dry and warm weather $\left(28-30^{\circ} \mathrm{C}\right)$, followed by wet weather two to three weeks after silking, favours disease incidence. To minimize the effect of FSR, several disease management methods have been suggested, including conventional tillage, crop rotation, foliar fungicide usage, and the deployment of resistant hybrids. Planting resistant cultivars are one of these measures that can significantly prevent disease growth and is highly advised (Ward et al., 1997). Breeding for resistance is a feasible and cost-effective way to manage soil-borne pathogens (Fehr, 1987). As a result, screening of maize germplasm has become a critical phase of maize breeding programs, where disease resistance selection leads to yield stability. Natural infection, on the other hand, will vary from year to year due to climatic factors and crop management practices. Henceforth, the creation of artificial epiphytotic inoculation methods can improve the reliability of the evaluation process and allow highly susceptible genotypes to be rejected from the breeding program.

\section{Materials and Methods}

\section{Plant material}

A total of 114 maize inbred lines (table3) assembled from different parts of the globe were evaluated along with two standard susceptible checks (Hema and Nithyashree) for FSR disease reaction under field condition at the College of Agriculture, V. C. Farm, Mandya, Karnataka with two replications under Randomized Complete Block Design (RCBD) planted during summer 2016. Each entry in each replication was planted in a $2 \mathrm{~m}$ row with spacing of $60 \times 20 \mathrm{~cm}$. Of the 114 inbreds screened, ten best lines (table2) that showed varied disease reactions against FSR were selected to produce all possible single cross hybrids (SCHs) in a diallel fashion during Kharif 2017 following recommended agronomic field practices. Artificial disease epiphytotic condition was created as screening protocol suggested by the Indian Institute of Maize Research (IIMR, New Delhi).

\section{Creation of artificial disease epiphytotic condition}

The diseased maize stalks exhibiting perfect FSR symptoms were identified and collected from all susceptible genotypes grown at the farm of College of Agriculture, V. C. Farm, Mandya. The disease-causing Fusarium moniliforme was isolated using the standard tissue isolation technique (IIMR), New Delhi. Pathogen isolations were done by plating surface sterilized (4 percent sodium hydrochloride) small pieces of infected tissues on potato dextrose agar (PDA) medium. Purification of cultures was made by the 
hyphal tip method. The fungal hyphae were aseptically transferred to culture plates containing the sterile PDA medium to get stock culture. The culture colour of $F$. moniliforme was pinkish white (Plate1) and confirmed by the shape of microconidia. The inoculum was mass multiplied on Petri plates (Plate4). The cultures of the fungus were subcultured on potato dextrose agar slants and kept in the laboratory at $28 \pm 1^{\circ} \mathrm{C}$ for 15 days. Further, these cultures were sub-cultured once a month and used for future studies. Inoculations were made with 45-50 days old plants just after the flowering stage, in the second internode above the soil level. The suspension of Fusarium culture was injected diagonally using the syringe after pricking and making a $2 \mathrm{~cm}$ hole with the help of jabber (Plate2 and 3). Disease symptoms appeared in the inoculated plants about 20-25 days after inoculation. The disease intensity and severity were recorded following a 1(highly resistant)9(highly susceptible) rating scale as described by IIMR (New Delhi) given in table1. Based on disease scoring scale, maize inbred lines and single cross hybrids were classified in to different disease reaction groups (Fig1 and 2; table5).

\section{Results and Discussion}

Due to its soil-borne infection pathway, fungicidal control of Fusarium stalk rot is not effective. However, to reduce disease-related losses while simultaneously boosting production to meet increasing demands, it is required to introduce a significant level of genetic resistance in breeding programs is advised and to combat yield losses caused by phytopathogens. For identification of resistance source to Fusarium stalk rot in maize, a total of 114 maize inbred lines were screened, and mean disease score and disease reaction was recorded by using the 1-9 disease rating scale suggested by IIMR, New Delhi during summer 2016. The results about the mean disease score of inbred lines are presented in table3 along with the standard error of the mean (SEm \pm ) and critical difference (CD). Similarly, all 45 single cross hybrids were screened against FSR to identify a resistant cross combination during Kharif 2017(table4).

Out of 114 maize inbred lines screened against Fusarium stalk rot, four genotypes viz., CM 202, 10878, MAI-759 and MAI-766 showed moderately resistant reaction with a mean disease score of 3-4. While, 20 genotypes viz., MAI-215, MAI-272, MAI-279, 18683, MAI250, MAI-257, MAI-283, MAI-293, MAI306, MAI-307, 33189, MAI-300, 31837, MAI-320, MAI-329, MAI-395, MAI-753, MAI-754, MAI-762, MAI-764 and MAI-767 expressed moderately susceptible reaction with mean disease score of 4-5. Fifty-two genotypes showed susceptible reaction and 38 genotypes recorded highly susceptible disease reactions with mean disease scores of 5-6 and $6-9$, respectively (fig1). In the present study, a total of 114 maize genotypes were screened for identification of resistance sources to Fusarium stalk rot. Out of which only two inbreds viz., CM202 (3.00) and MAI 766 (3.40) expressed moderately resistant reaction. Fasihi et al., (2013), also reported resistance in the inbred MO17 to Fusarium verticillioides under field conditions. As Hooker and Draganic (1980), suggested that one resistant inbred parent is sufficient for obtaining a hybrid resistance to stalk rot. Hence the inbred line CM202 possessing moderate resistance to stalk rot would be valuable breeding stock for use as a parent for the development of resistant hybrids. Out of 114 genotypes, 15 inbreds expressed moderately susceptible reaction against Fusarium stalk rot with disease score of (4-5).

These results were in confirmation with Qureshi et al., (2015), wherein they reported 13 inbred lines as moderately susceptible. A 
total of 68 and 57 genotypes showed highly susceptible and susceptible reaction. Even Afolabi et al., (2008), also reported six inbred lines with high levels of disease susceptibility. The mean disease scale ranged between 3.05 to 6.75 (table2) among ten parents used in producing all possible cross combinations while, in crosses, the range was from 2.60 to
7.25 (table4). Among 45 single crosses, only the cross MAI329 $\times$ CM202 (mean disease score was 2.60) exhibited resistance reaction against Fusarium stalk rot but the checks Nithyashree and Hema recorded susceptible reaction with mean disease scores of 5.4 and 6.2 , respectively.

Table.1 Disease rating scale: (IIMR, New Delhi; Hooker, 1956)

\begin{tabular}{|c|c|c|}
\hline $\begin{array}{c}\text { Disease } \\
\text { score }\end{array}$ & $\begin{array}{l}\text { Disease } \\
\text { reaction }\end{array}$ & Symptoms \\
\hline $\mathbf{1}$ & HR & Healthy or slight discolouration at the site of inoculation \\
\hline 2 & $\mathbf{R}$ & Up to $50 \%$ of the inoculated internode is discoloured \\
\hline 3 & MR & $51-75 \%$ of the inoculated internode is discoloured \\
\hline 4 & MS & $76-100 \%$ of the inoculated internode is discoloured \\
\hline 5 & $\mathbf{S}$ & Less than $50 \%$ discolouration of the adjacent internode \\
\hline 6 & HS & More than $50 \%$ discolouration of the adjacent internode \\
\hline 7 & HS & Discolouration of three internodes \\
\hline 8 & HS & Discolouration of four internodes \\
\hline 9 & HS & $\begin{array}{c}\text { Discolouration of five internodes and premature death of } \\
\text { plant }\end{array}$ \\
\hline
\end{tabular}

Note: HR: Highly resistant, R: Resistance, MR: Moderately Resistance, MS: Moderately susceptible, S: Susceptible, HS: Highly susceptible

Table.2 List of 10 best parents used in the production of single cross hybrids

\begin{tabular}{|c|c|c|c|}
\hline Sl. No. & Genotype & Disease score & Disease reaction \\
\hline $\mathbf{1}$ & CM202 & $2.50-3.00$ & MR \\
\hline $\mathbf{2}$ & MAI766 & 3.00 & MR \\
\hline $\mathbf{3}$ & 10878 & 3.60 & MR \\
\hline $\mathbf{4}$ & 31837 & 4.30 & MS \\
\hline $\mathbf{5}$ & MAI329 & 4.00 & MS \\
\hline $\mathbf{6}$ & MAI754 & 4.00 & MS \\
\hline $\mathbf{7}$ & VL109287 & 5.30 & S \\
\hline $\mathbf{8}$ & VL108867 & 7.00 & HS \\
\hline $\mathbf{9}$ & VL1043 & 6.30 & HS \\
\hline $\mathbf{1 0}$ & VL1218 & 6.60 & HS \\
\hline $\mathbf{1 1}$ & Hema (Check) & $\mathbf{6 . 2 0}$ & HS \\
\hline $\mathbf{1 2}$ & Nithyashree (Check) & $\mathbf{5 . 4 0}$ & S \\
\hline
\end{tabular}


Table.3 Screening of inbred lines of maize for their reaction to Fusarium stalk rot

\begin{tabular}{|c|c|c|c|c|c|c|c|c|c|c|c|c|c|c|c|}
\hline Sl.No & Inbreds & DS & DR & Sl.No & Inbreds & DS & DR & Sl.No & Inbreds & DS & DR & Sl.No & Inbreds & DS & DR \\
\hline 1 & M-QPM-1 & 5.6 & $S$ & 31 & MAI-211 & 5.6 & $S$ & 61 & 33189 & 4.6 & MS & 91 & VL1043 & 6.3 & HS \\
\hline 3 & M-QPM-4 & 5.3 & $\mathrm{~S}$ & 33 & MAI-213 & 6.0 & HS & 63 & MAI-322 & 5.6 & $\mathrm{~S}$ & 93 & VL109287 & 5.3 & S \\
\hline 5 & M-QPM-7 & 5.0 & S & 35 & MAI-215 & 5.6 & $S$ & 65 & 33174 & 6.0 & HS & 95 & VL109452 & 6.0 & HS \\
\hline 6 & M-QPM-10 & 6.6 & HS & 36 & MAI-223 & 4.6 & MS & 66 & 32554 & 5.0 & $S$ & 96 & VL121096 & 7.0 & HS \\
\hline 7 & M-QPM-12 & 6.0 & HS & 37 & MAI-250 & 4.0 & MS & 67 & MAI-332 & 5.6 & S & 97 & VL1218 & 6.6 & HS \\
\hline 10 & MAI-21 & 5.3 & $\mathrm{~S}$ & 40 & MAI-257 & 4.3 & MS & 70 & MAI-386 & 5.6 & $S$ & 100 & CML-9 & 6.0 & HS \\
\hline 11 & M-QPM-22 & 5.3 & $\mathrm{~S}$ & 41 & MAI-266 & 5.3 & $S$ & 71 & MAI-391 & 5.0 & $S$ & 101 & CML-16 & 5.0 & S \\
\hline 12 & MAI-28 & 5.3 & S & 42 & MAI-267 & 5.3 & S & 72 & MAI-395 & 4.6 & MS & 102 & CML-17 & 5.6 & $S$ \\
\hline 13 & M-QPM-33 & 6.0 & HS & 43 & MAI-268 & 5.3 & S & 73 & MAI-702 & 6.3 & HS & 103 & CML-20 & 5.0 & $S$ \\
\hline 14 & M-QPM-35 & 6.0 & HS & 44 & MAI-272 & 4.6 & MS & 74 & MAI-727 & 5.3 & $\mathrm{~S}$ & 104 & CML-21 & 5.0 & S \\
\hline 15 & M-QPM-38 & 6.0 & HS & 45 & MAI-279 & 4.6 & MS & 75 & MAI-740 & 5.0 & $\mathrm{~S}$ & 105 & CML-22 & 6.0 & HS \\
\hline 20 & 10878 & 3.6 & MR & 50 & MAI-293 & 4.0 & MS & 80 & MAI-758 & 5.3 & $\mathrm{~S}$ & 110 & CML-39 & 6.3 & HS \\
\hline 21 & MAI-134 & 6.0 & HS & 51 & MAI-306 & 4.3 & MS & 81 & MAI-759 & 3.6 & MR & 111 & CML-153 & 6.0 & HS \\
\hline 22 & MAI-135 & 5.3 & $\mathrm{~S}$ & 52 & MAI-307 & 4.6 & MS & 82 & MAI-762 & 4.6 & MS & 112 & CML-137 & 7.3 & HS \\
\hline 23 & MAI-137 & 6.3 & HS & 53 & MAI-310 & 5.3 & $S$ & 83 & MAI-764 & 4.6 & MS & 113 & CML-139 & 6.0 & HS \\
\hline 24 & MAI-150 & 6.0 & HS & 54 & 31810 & 5.3 & $S$ & 84 & MAI-766 & 3.0 & MR & 114 & CM202 & 3.0 & MR \\
\hline 25 & MAI-155 & 5.6 & S & 55 & 31837 & 4.3 & MS & 85 & MAI-767 & 4.6 & MS & & S Em \pm & 0.48 & \\
\hline 26 & MAI-175 & 5.6 & S & 56 & MAI-320 & 4.3 & MS & 86 & VL05550 & 6.3 & HS & & CD@5\% & 1.34 & \\
\hline 27 & MAI-182 & 6.3 & HS & 57 & 32427 & 5.0 & S & 87 & VL073318 & 5.0 & S & \multirow{2}{*}{\multicolumn{4}{|c|}{ Total }} \\
\hline 28 & 18683 & 4.3 & MS & 58 & 32645 & 5.0 & $S$ & 88 & VL1012849 & 5.3 & S & & & & \\
\hline 29 & MAI-202 & 6.3 & HS & 59 & 32810 & 5.0 & $S$ & 89 & VL1018792 & 7.0 & HS & MR & 4 & $\mathbf{S}$ & 38 \\
\hline 30 & MAI-206 & 6.6 & HS & 60 & MAI-329 & 4.0 & MS & 90 & VL1033 & 7.0 & HS & MS & 19 & HS & 54 \\
\hline
\end{tabular}

Note: DS: Disease Score, DR: Disease reaction, HR: Highly resistant, R: Resistance, MR: Moderately Resistance, MS: Moderately susceptible, S: Susceptible, HS: Highly susceptible 
Table.4 Screening of single cross hybrids of maize for their reaction to Fusarium stalk rot

\begin{tabular}{|c|c|c|c|c|c|c|c|c|c|c|c|}
\hline Sl.No & SCHs & DS & DR & Sl.No & SCHs & DS & DR & Sl.No & SCHs & DS & DR \\
\hline 1 & MAI-766 ×CM202 & 5.10 & S & 19 & VL109287×VL108867 & 5.00 & $\mathrm{~S}$ & 37 & VL1043×10878 & 6.80 & HS \\
\hline 2 & MAI-329 $\times$ CM202 & 2.60 & $\mathbf{R}$ & 20 & VL1218 ×VL1043 & 4.38 & MS & 38 & VL1218 $\times 10878$ & 5.50 & $\mathrm{~S}$ \\
\hline 3 & MAI-754×CM202 & 4.25 & MS & 21 & $10878 \times$ MAI-329 & 6.00 & HS & 39 & VL109287×10878 & 6.50 & HS \\
\hline 4 & $10878 \times \mathrm{CM} 202$ & 4.38 & MS & 22 & $31837 \times \mathrm{MAI}-329$ & 6.40 & HS & 40 & VL108867×31837 & 7.00 & HS \\
\hline 5 & $31837 \times \mathrm{CM} 202$ & 5.45 & S & 23 & VL108867×MAI-329 & 5.80 & S & 41 & VL1043×31837 & 6.25 & HS \\
\hline 6 & VL108867×CM202 & 4.40 & MS & 24 & VL1043×MAI-329 & 5.60 & S & 42 & VL1218×31837 & 6.00 & HS \\
\hline 7 & VL1043× CM202 & 5.85 & $\mathrm{~S}$ & 25 & VL1218 ×MAI-329 & 5.75 & $\mathrm{~S}$ & 43 & VL109287×31837 & 6.63 & HS \\
\hline 8 & VL1218×CM202 & 4.60 & MS & 26 & VL109287×MAI-329 & 6.25 & HS & 44 & VL1043×VL108867 & 5.30 & $\mathrm{~S}$ \\
\hline 9 & VL109287×CM202 & 6.10 & HS & 27 & $10878 \times$ MAI-754 & 7.25 & HS & 45 & VL1218×VL108867 & 4.40 & MS \\
\hline 10 & MAI-329×MAI-766 & 5.25 & S & 28 & $31837 \times \mathrm{MAI}-754$ & 6.20 & HS & 46 & $\begin{array}{l}\text { Nithyashree } \\
\text { (Check) }\end{array}$ & 5.40 & $\mathrm{~S}$ \\
\hline 11 & MAI-754×MAI-766 & 5.85 & S & 29 & VL108867×MAI-754 & 5.63 & $\mathrm{~S}$ & 47 & Hema (check) & 6.20 & HS \\
\hline 12 & $10878 \times$ MAI-766 & 6.10 & HS & 30 & VL1043×MAI-754 & 6.38 & HS & & Grand Mean & 5.65 & \\
\hline 13 & $31837 \times$ MAI-766 & 6.50 & HS & 31 & VL1218 ×MAI-745 & 6.25 & HS & & Range & $\begin{array}{l}2.6- \\
7.25\end{array}$ & \\
\hline 14 & VL108867×MAI-766 & 6.38 & HS & 32 & VL109287×MAI-754 & 5.63 & $\mathrm{~S}$ & & SEm \pm & 0.32 & \\
\hline 15 & VL1043×MAI-766 & 5.60 & $\mathrm{~S}$ & 33 & $31837 \times 10878$ & 6.30 & HS & & C.D. @ 0.05 & 0.64 & \\
\hline 16 & VL1218 ×MAI-766 & 5.63 & $\mathrm{~S}$ & 34 & VL108867×10878 & 6.63 & HS & & C.D. @ 0.01 & 0.86 & \\
\hline 17 & VL109287×MAI-766 & 6.22 & HS & 35 & VL109287×VL1043 & 5.25 & $\mathrm{~S}$ & & & & \\
\hline 18 & MAI-754×MAI-329 & 4.75 & MS & 36 & VL109287×VL1218 & 4.10 & MS & & & & \\
\hline
\end{tabular}

Note: DS: Disease Score, DR: Disease reaction, HR: Highly resistant, R: Resistance, MR: Moderately Resistance, MS: Moderately susceptible, S: Susceptible, HS: Highly susceptible 
Table.5 Grouping of maize inbreds and single cross hybrids based on Fusarium stalk rot disease reaction

\begin{tabular}{|c|c|c|c|c|c|}
\hline Sl.no. & DR & Name of the Inbreds & Name of the SCHs & DS & Total coun \\
\hline 1. & HR & - & - & 1 & 0 \\
\hline 2. & $\mathrm{R}$ & - & MAI-329 $\times$ CM202 & $2-2.9$ & 1 \\
\hline 3. & MR & MAI-766,CM202,10878,MAI-759 & - & $3-3.9$ & 4 \\
\hline 4. & MS & $\begin{array}{c}\text { MAI- } \\
250,283,293,329,753,754,257,306,320,223,2 \\
72,279 \\
307,395,762,764,767,18683,31837,33189,\end{array}$ & 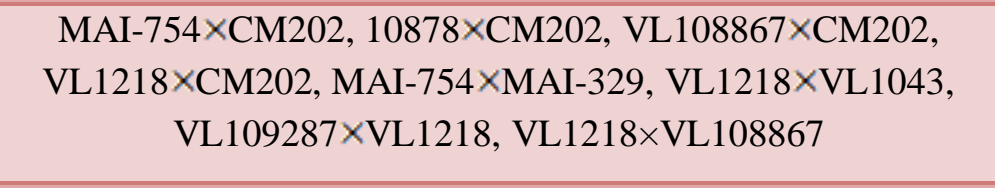 & $4-4.9$ & 28 \\
\hline 5. & S & $\begin{array}{c}\text { M-QPM-5,M-QPM-7,MAI-252,285, } \\
\text { 391,740,32427,32654,32810,32554,VL07331 } \\
\text { 8,VL109449,CML-16,20,21,31,M-QPM- } \\
\text { 4,MAI-13,21,M-QPM-22,MAI- } \\
\text { 28,135,214,10250,MAI- } \\
\text { 266,267,268,310,333,727,31810,VL1012849, } \\
\text { VL109287,CML-23,M-QPM-1,M-QPM- } \\
\text { 39,MAI- } \\
\text { 103,155,175,211,215,282,292,322,32785,M } \\
\text { AI-332,746,751,CML-17,CML-35 }\end{array}$ & 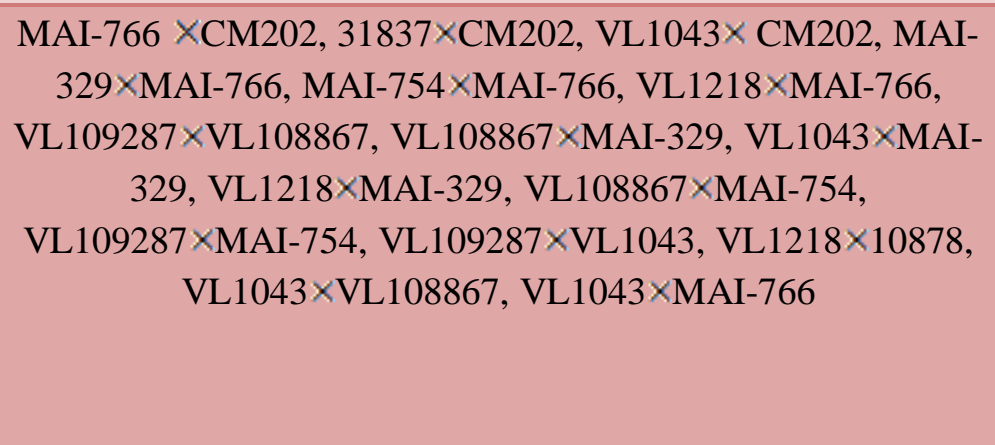 & $5-5.9$ & 51 \\
\hline 6. & HS & $\begin{array}{c}\text { M-QPM-2,12,33,38,10,MAI- } \\
\text { 14,134,150,213,364,137,182,202,212,702,40, } \\
\text { 206,CML- } \\
\text { 4,37,137,39,9,22,153,139, VL109452,VL055 } \\
\text { 50, VL1043, VL1218, VL1236,VL1018792,V } \\
\text { L1033, VL108867,VL121096,33189- } \\
\text { 1,33174,10269 }\end{array}$ & 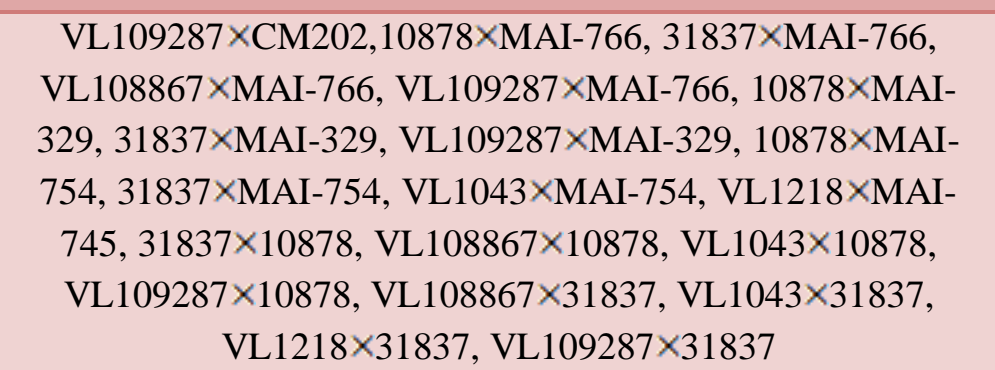 & $6-9$ & 75 \\
\hline
\end{tabular}

Note: DS: Disease Score, DR: Disease reaction, HR: Highly resistant, R: Resistance, MR: Moderately Resistance, MS: Moderately susceptible, S: Susceptible, HS: Highly susceptible 
Plate.1 Culture colour of Fusarium moniliforme

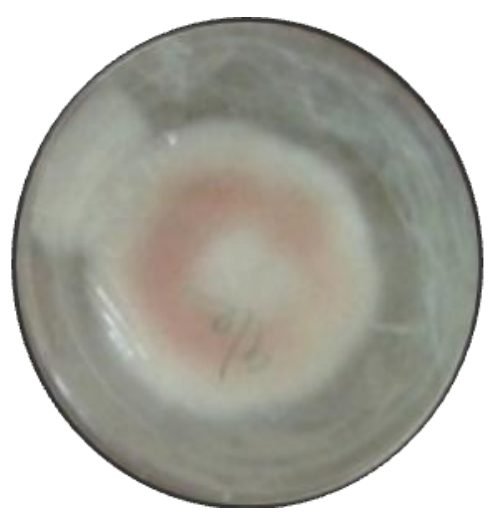

Plate. 2 and 3 Syringe method of inoculation

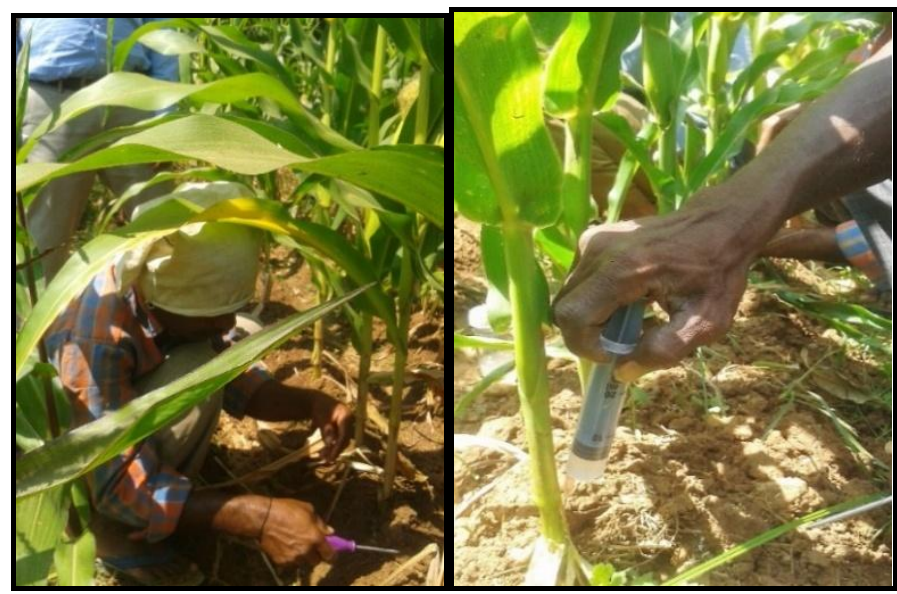

Plate.4 Mass multiplication of Fusarium culture on Petri plates

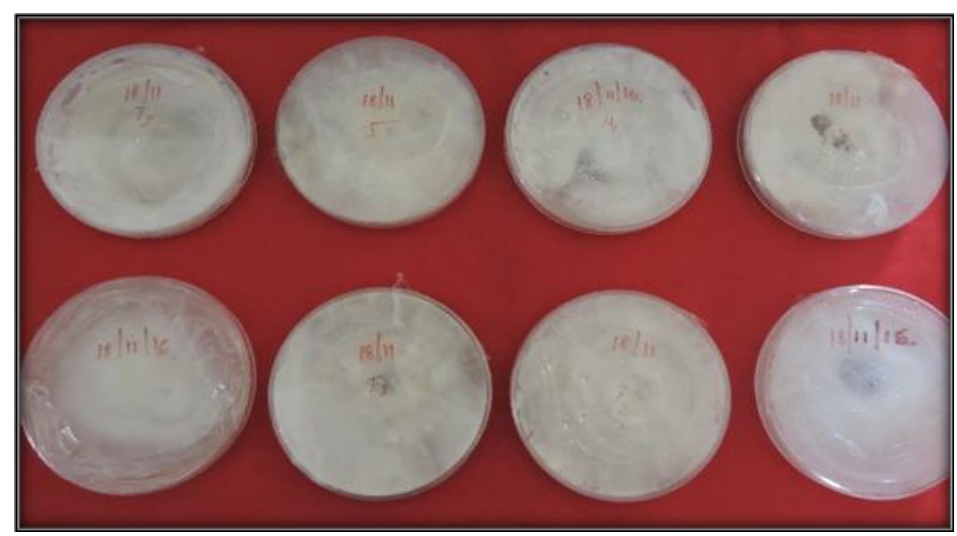

Fig 1. The maize inbred lines showed varied disease reactions against Fusarium stalk rot (FSR) screened under artificial epiphytotic conditions

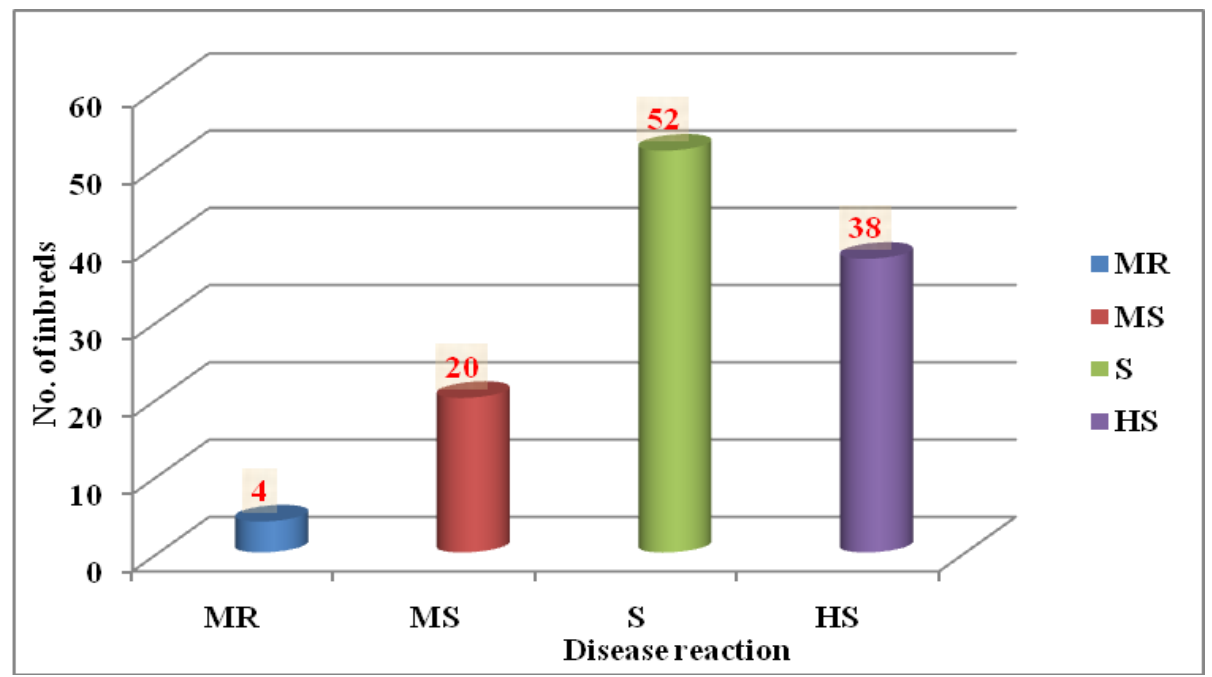


Fig 2. Screening of single cross hybrids $(\mathrm{SCH})$ against Fusarium stalk rot (FSR) under artificial epiphytotic conditions

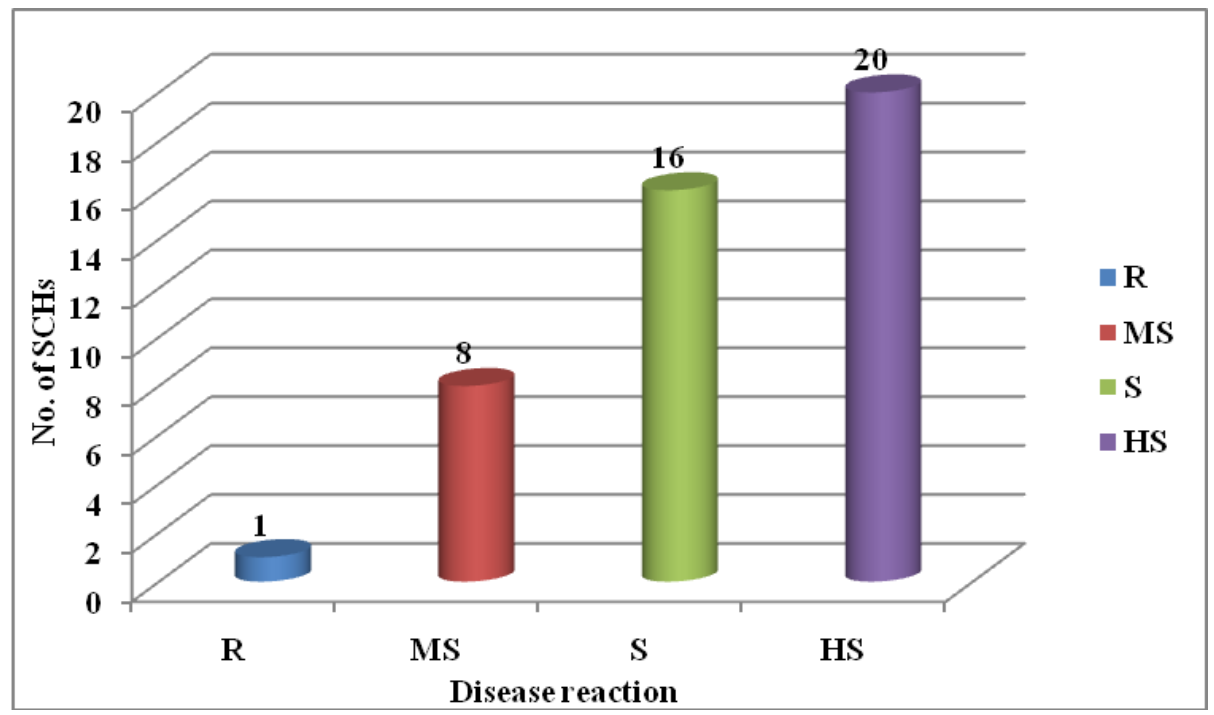

Therefore, the cross MAI329 × CM202 with high grain yield and resistance to Fusarium stalk rot needs to be evaluated in extensive yield trials for release as a new hybrid. Of the 45 SCHs, eight single crosses viz., MAI754×CM202, 10878×CM202, VL108867× CM202, VL1218×CM202, MAI-754×MAI329, VL1218×VL1043, VL109287 ×VL1218, VL1218×VL108867 showed moderately susceptible disease reaction towards FSR with a mean disease score range of 4-4.9. While 16 cross combinations showed susceptible reaction and 20 single crosses exhibited highly susceptible reaction against FSR disease with mean disease scores of 5-5.9 and 6-9, respectively (fig2). An earlier report by Ledencan et al., (2003), suggests that testing against FSR needs to be screened in both inbred lines and hybrids. Based on the mean disease rating scale maize inbred lines and single cross hybrids were classified into different disease reaction groups (table5). Screening and genetic evaluation of germplasm against biotic stresses is an integral part of any breeding program. Since Fusarium monilifome is a soil-borne pathogen, breeding and deployment of resistant cultivars having good agronomic performance are recommended over other means of combating yield losses by the pathogen around the globe.

\section{References}

Afolabi, C. G., Ojiambo, P. S., Ekpo, E. J. A., Menkir, A. and Bandyopadhyay, R. 2008. Novel sources of resistance to Fusarium stalk rot of maize in tropical Africa. Pl. Dis., 92(5): 772-780.

Fasihi, V., Valizadeh, M., Shiri, M. and Imani, A. A. 2013. The Survey of Maize Inbred Lines for Resistance to Fusarium verticillioides Ear Rot. J. Appl. Environ. Biol. Sci., 3(11): 107110.

Fehr, W. R., 1987. Principles of Cultivar Development. PB: Macmillan. New York. USA.

Holbert, J. R., 1924. Corn root, stalk, and ear rot diseases, and their control thru seed selection and breeding (Vol. 255). University of Illinois Agricultural Experiment Station.

Hooker, A. L., 1956. Association of resistance to several seedling, root, stalk, and ear diseases of corn. Phytopatho., 46, 379384. 
Hooker, A. L. and Draganic, M. 1980. Maize stalk rot ratings and predicting hybrid reaction from parental inbred reaction. Genet., 12, 319-330.

Jat, A., 2016. Source of Resistance and Management of Post Flowering Stalk Rot (PFSR) of Specialty Corn Caused by Fusarium verticillioides Sheldon (Doctoral dissertation, MPUAT, Udaipur).

Ledencan, T., Simic, D., Brkic, I., Jambrovic, A. and Zdunic, Z. 2003. Resistance of maize inbreds and their hybrids to Fusarium Stalk Rot.Czech J. Genet. Pl. Breed., 39(1): 15-20.

Liu, K., Goodman, M., Muse, S., Smith, J. S., Buckler, E. D., \& Doebley, J. 2003. Genetic structure and diversity among maize inbred lines as inferred from DNA microsatellites. Genetics, 165(4): 2117-2128.

Munkvold, G. P., 2003. Epidemiology of Fusarium diseases and their mycotoxins in maize ears. Europian $\mathrm{J}$. Pl. Pathol., 109,705-713.

Oerke, E. C., 2005. Crop losses to pest. J. Aric. sci., 143: 1-13.

Power, A. G., 1987. Plant community diversity, herbivore movement, and an insect-transmitted disease of maize. Ecology, 68(6): 1658-1669.

Qureshi, S. H., Qayyum, A. and Fiers, W. 2015. Sources of genetic resistance in maize to Fusarium stalk rot and their variations at molecular level. Turk. J. Agric. For., 39, 503-513.

Rahul, K. and Singh, I. S., 2002. Inheritance of resistance to banded leaf and sheath blight of Maize. In: Proc. $8^{\text {th }}$ Asian regional maize works. Bangkok, Thailand, 5,356-365.

Tabassum, A., Kumar, V. S. and Kumar, N. K. 2020. Screening of Maize Germplasm for Resistance against Fusarium Stalk Rot caused by Fusarium verticillioides. Int. J. Curr. Microbiol. App. Sci., 9(5): 3155-3160.

Ward J. M. J., Laing M.D. and Rijkenberg F. H. J. 1997. Frequency and timing of fungicide applications for the control of gray leaf spot in maize. Plant Disease, 81, 141-148.

Troyer A. F., 2006. Adaptedness and heterosis in corn and mule hybrids. Crop Sci., $46,528-548$.

\section{How to cite this article:}

Archana, R., H. C. Lohithaswa, R. Pavan, B. N. Swathi and Mallikarjuna, N. 2021. Genetic Testing of Inbred Lines and Single Cross Hybrids against Fusarium Stalk Rot Caused by Fusarium moniliforme in Maize (Zea mays L.). Int.J.Curr.Microbiol.App.Sci. 10(11): 352-361. doi: https://doi.org/10.20546/ijcmas.2021.1011.040 